\title{
Dye-Sensitized Solar Cells: Components Screening for Glass substrate, Counter-Electrode, Photoanode and Electrolyte
}

\author{
Adriano dos S. Marques ${ }^{a, b}$, Vitor A. S. da Silva ${ }^{a}$,Emerson S. Ribeiro ${ }^{b}$ (), Luiz F. B. Malta ${ }^{a^{*}}$ \\ ${ }^{a}$ Universidade Federal do Rio de Janeiro, Instituto de Química, Laboratório de Química \\ Supramolecular e de Sólidos (LQSS), Rio de Janeiro, RJ, Brasil. \\ ${ }^{b}$ Universidade Federal do Rio de Janeiro, Instituto de Química, Laboratório de Desenvolvimento e \\ Aplicações de Novos Materiais (LaDANM), Rio de Janeiro, RJ, Brasil.
}

Received: April 23, 2020; Revised: July 05, 2020; Accepted: August 26, 2020.

The dye-sensitized solar cells (DSSC) represents a viable and low-cost alternative to generate electrical power by the sunlight. In the present work, the DSSC components such as glass substrate (ITO/ FTO), counter-electrode (graphite/platinum), photoanode components (use or not of AuNPs as Shottky barriers) and electrolyte concentration and components were screened to understand their influence on device operation. FTO substrates and Pt counter-electrode were shown to perform best. However, the use of such metal does not comply with the device low cost approach. Gold nanoparticles in the photoanode did not result in an increase of efficiency. Finally, the electrolyte composition influenced the device performance: it was observed that the highest efficiency was obtained for the electrolytes containing 4-tert-butylpyridine together with smaller cations (such as $\mathrm{Na}$ and $\mathrm{K}$ ) as counter-ions to triiodide. The highest efficiency achieved in this work was $1.26 \%$.

Keywords: DSSC, gold nanoparticles, Counter-electrode, Electrolyte Composition, Low-Cost Approach.

\section{Introduction}

The 4.0 technological revolution along with modern lifestyle and 4.0 industrialization will require a $56 \%$ increase of world energy consumption in the next 30 years ${ }^{1}$. By 2050 the projection shows that this consumption will become 30 TW and will more than triple by the end of the century ${ }^{2}$. Much of the energy produced worldwide relies on fossil fuel sources that release $\mathrm{CO}_{2}$ and $\mathrm{NOx}$ into the atmosphere, causing environmental damage such as the greenhouse effect and acid rain. There is a growing worldwide demand for the use of energy from renewable sources rather than from fossil fuels. This demand has encouraged a wide range of research activities in various areas, including development in the field of photovoltaic cells. These cells, also known as solar cells, assume the photovoltaic effect that occurs in a pn junction of doped semiconductors, with consequent current flowing through an external circuit after the illumination of this junction.

In 1991, Grätzel and O'Regan ${ }^{3}$ proposed a solar cell employing relatively inexpensive materials to mimic the process of photosynthesis that occurs in nature. This device became known as Dye Sensitized Solar Cell (DSSC) or Grätzel Cell. Since the beginning of Grätzel cell research, the main interest of the studies has been to increase the efficiency of the device so that they can become a viable alternative to current technologies involving silicon, whose efficiency is around 17 to $24 \%{ }^{4}$. The focus of research on devices is directed to two main areas: dyes and photoanode, which together account for more than half of publications in the area ${ }^{5}$.

*e-mail:lfbmalta@iq.ufrj.br
In the photoanode part there are several studies involving changes in semiconductor morphology in search of efficiency improvement, such as titanium ${ }^{6}$ and zinc $^{7}$ oxide nanorods, nanotubes ${ }^{8}$, nanosheets ${ }^{9}$, hierarchical nanosheets and nanobeads ${ }^{10}$; however the yield gain generated by these changes is usually low. Composite forms were also tested, as $\mathrm{TiO}_{2} /$ graphene oxide/Ag nanofibers, with increased efficiency in relation to standard DSSC ${ }^{11}$. Other materials were used as photoanodes such as tin oxide ${ }^{12}$, cerium oxide ${ }^{13,14}$ and antimonium oxide ${ }^{15}$ though not as successfully as titanium and zinc oxides.

Efforts to reduce electron recombination through the use of metallic nanoparticles has been the subject of past works ${ }^{16-18}$ who have used titanium oxide and gold nanoparticles sensitized with ruthenium dye N719, leading to an efficiency increase of about $1 \%$ for the first two studies compared to cells containing only titanium oxide under the same conditions; for Ghaffari et al. ${ }^{18}$ the result was less expressive. Wang's study compares nanoparticle size and device performance, finding better results for cells with the largest nanoparticles. In addition to charge transfer improvement a recent paper reported the enhancement of dye absorption due to AuNPs plasmon resonance ${ }^{19}$.

Regarding ruthenium dyes the maximum efficiency reached is $11.4 \%{ }^{20}$. Over the years there has been little growth in cell efficiency using this type of dyes, motivating the study of other compounds for substitution. Cells employing organic dyes perform similarly to those using ruthenium complexes facing the same difficulty in achieving efficiency, including those employing extracts of natural dyes $^{21}$. Dyes based on porphyrinic structures have obtained 
promising results, surpassing devices that use ruthenium. The works reported in the literature use the knowledge acquired with organic dyes and apply those together with porphyrins, so electron donor and acceptor structures are added to porphyrins and the porphyrinic core acts as the $\pi$ spacer of organic dyes. This recent approach ${ }^{22,23}$ has led to efficiencies of $13 \%$ using zinc metal porphyrins and cobalt II / III complexes as electrolyte.

In its turn perovskite solar cells (PSCs) have increased cell efficiencies (c.a. $23 \%$ ) by widening solar-light absorption having narrower bandgaps ${ }^{24}$. Lead perovskites of formula $\mathrm{CH}_{3} \mathrm{NH}_{3} \mathrm{PbX}_{3}$ has been employed, where $\mathrm{X}$ is a halogen. However, there are still issues to be resolved such as stability, as the perovskite degrades in contact with moisture and also in excessive heat ${ }^{25}$. Another concern is the environmental factor as the lead used in this material is known to be a toxic element to nature, although some candidate materials for $\mathrm{Pb}$ substitution with perovskite structure exhibiting low toxicity are now being studied ${ }^{26}$.

The contribution of the present manuscript relates to the study of the operation conditions for the Dye-sensitized solar cell. Since there is a plethora of works describing a multitude of diverse conditions for some components of DSSC this screening study turns out to be a clarifying way to settle the best conditions for cell performance. Applying some of the already described components for photoanode, counterelectrode, electrolyte and conducting glass simultaneously in one unique optimization work is of interest for exploring the maximum efficiency of this device.

\section{Experimental}

\subsection{Physical methods}

Ultraviolet-visible diffuse reflectance spectroscopy spectra were acquired on a SHIMADZU model UV-2600 apparatus using the ISR-2600 integration sphere. The samples were measured using a $90^{\circ}$ incidence angle for the radiation beam in the range of $200 \mathrm{~nm}$ to $900 \mathrm{~nm}$.

$\mathrm{X}$-ray diffraction patterns were acquired on a Rigaku Ultima IV diffractometer with high-frequency x-ray generator ( $3 \mathrm{~kW}), \mathrm{Cu}$-ray tube $(\alpha=1.5418 \AA \hat{)})$, normal focus $(2 \mathrm{~kW})$, universal goniometer with radius of $185 \mathrm{~mm}$, fixed slits and Kbeta Ni filter, with voltage of $40 \mathrm{kV}$ and current of $20 \mathrm{~mA}$. Samples were analyzed supported on glass sample holders. The analyzed range was $5^{\circ}<2 \theta<90^{\circ}$, with a step of $0.02^{\circ}$ and time per step of $1 \mathrm{~s}$.

TGA and DTA curves were performed on a SHIMADZU analyzer, model DTG-60. The samples were analyzed in the range of $298 \mathrm{~K}$ to $1,073 \mathrm{~K}$ with heating rate of $10 \mathrm{~K} \mathrm{~min}^{-1}$ under the argon flow of $50 \mathrm{~mL} \mathrm{~min}^{-1}$.

Scanning electron microscope (SEM) images were performed on a JEOL JSM 6460-LV microscope operating among 10-20 kV and equipped with an energy-disperse $\mathrm{X}$-ray spectrometer.

Electrochemical behavior analysis was performed on an Autolab potentiostat/galvanostat (model 128N) using the LED Driver kit. The analyzes took place from 0 to 1 Volt with illumination by the warm white LED with power calibrated at $100 \mathrm{~mW} / \mathrm{cm}^{2}$.

\subsection{Materials and methods}

\subsubsection{Preparation of $\mathrm{TiO}_{2}$ suspension}

To prepare the $\mathrm{TiO}_{2}$ suspension for film making, $3.0 \times 10^{-2} \mathrm{~g}$ of anatase phase $\mathrm{TiO}_{2}$ (Sigma-Aldrich) with mean particle size smaller than $25 \mathrm{~nm}$ were suspended in $50 \times 10^{-6} \mathrm{~L}$ milli-Q water and submitted to ultrasound sonication for $5 \mathrm{~min}$.

\subsubsection{Photoanode preparation}

Photoanode preparation occurred from semiconductor oxide suspensions. First glass substrates ITO (Sigma-Aldrich, $8.0-12.0 \Omega / \mathrm{cm}^{2}$ resistivity) or FTO (Sigma Aldrich, $7 \Omega / \mathrm{cm}^{2}$ resistivity) were cleaned with ethanol P.A. (Vetec). The deposition of the film occurred by the tape casting method: first an area on the substrate was delimited using an adhesive tape, then $20 \times 10^{-6} \mathrm{~L}$ of the previously prepared semiconductor suspension was dripped above the limited area. Using a microscope slide the suspension was dragged across the substrate, filling the demarcated area, thus creating a film. After drying the film, the tape was removed, and the film was sintered at $723 \mathrm{~K}$ for 30 minutes. The sintered film was then immersed for 24 hours in the $0.50 \times 10^{-3} \mathrm{~mol} \mathrm{~L}^{-1}$ solution of $\mathrm{N} 3$ dye $\left(\mathrm{C}_{26} \mathrm{H}_{16} \mathrm{~N}_{6} \mathrm{O}_{8} \mathrm{RuS}_{2}\right.$, Sigma Aldrich $)$ in ethanol.

\subsubsection{AuNPs preparation and impregnation}

The gold nanoparticles were prepared and impregnated using several ways. In the first form to synthesize the gold NPs, they were prepared by the citrate method: a $50.0 \times 10^{-3} \mathrm{~L}$ flask was used where $1.98 \times 10^{-2} \mathrm{~g} \mathrm{NaAuCl}_{4} .2 \mathrm{H}_{2} \mathrm{O}(4.97$ x $10^{-5}$ mol, Sigma-Aldrich) was solubilized in $25 \times 10^{-3}$ L Milli-Q water. This solution was then heated to $363 \mathrm{~K}$ and then $5.88 \times 10^{-2} \mathrm{~g}$ of sodium citrate $\left(2.00 \times 10^{-4} \mathrm{~mol}\right.$, J.T.Baker Chemical) was added and the resulting solution was allowed to reflux for 1 hour at $363 \mathrm{~K}$. After the addition of sodium citrate, the solution changed its color to purple, characterizing the formation of gold nanoparticles ${ }^{27}$.

The impregnation of the gold nanoparticles, previously produced by the citrate method, on $\mathrm{TiO}_{2}$ occurred via two ways. Firstly, wet impregnation aimed to obtain titania with $1 \%$ gold by weight. To this end, $15.3 \times 10^{-3} \mathrm{~L}$ of the previously obtained $2.00 \times 10^{-3} \mathrm{~mol} \mathrm{~L}^{-1}$ gold nanoparticles solution was diluted to the final volume of $2.5 \times 10^{-2} \mathrm{~L}$. To this $1.22 \times 10^{-3} \mathrm{~mol} \mathrm{~L}^{-1}$ solution it was added $6.0 \times 10^{-1} \mathrm{~g}$ of $\mathrm{TiO}_{2}$ (Sigma-Aldrich) which was stirred for 24 hours. After this time the suspension was centrifuged, thus obtaining a purple solid which was allowed to dry at room temperature and subsequently ground in an agate mortar. This material was divided into three parts, one of which was calcined for $30 \mathrm{~min}$. at $723 \mathrm{~K}$; another part at $1,073 \mathrm{~K}$; and the third was not heated. The powders obtained with and without calcination at $1,073 \mathrm{~K}$ were used to make the photoanode for photovoltaic testing by the method described in the photoanode preparation section.

The second NPs impregnation method was performed using a variation of the wet impregnation procedure also in order to obtain the impregnated titania with $1 \%$ by weight in gold. In this method, $6.0 \times 10^{-1} \mathrm{~g}$ of $\mathrm{TiO}_{2}$ (Sigma-Aldrich) was added to $2.5 \times 10^{-3} \mathrm{~L}$ of a previously synthesized $1.22 \times 10^{-3} \mathrm{~mol} \mathrm{~L}^{-1}$ aqueous dispersion of gold nanoparticles, 
this time stirring to dryness: therefore, this method was named solvent evaporation impregnation. Subsequently, the resulting solid was ground in an agate mortar and the photoanode was made with this material as described in the photoanode preparation section.

The last method joined the AuNPs preparation and impregnation on $\mathrm{TiO}_{2}$ aiming at the intimate contact between oxide matrix and gold nanoparticles thus being denominated intimate impregnation. It was based on the work of Bora et al. ${ }^{28}$ and collaborators. First the $\mathrm{TiO}_{2}$ film was deposited on the substrate as shown in the photoanode preparation section. Subsequently the film substrate was immersed for 1 hour in a $1.0 \times 10^{-4} \mathrm{~mol} \mathrm{~L}^{-1}$ solution of $\mathrm{HAuCl}_{4} \cdot 3 \mathrm{H}_{2} \mathrm{O}$ (SigmaAldrich). After this period the substrate with the film was removed from this solution and placed on a heating plate at $373 \mathrm{~K}$. A $1.85 \times 10^{-3} \mathrm{~mol} \mathrm{~L}^{-1}$ sodium citrate aqueous solution was then slowly dropped on the film to reduce gold in situ. As the citrate solution evaporated, more was added, totaling $6.0 \times 10^{-4} \mathrm{~L}$ of citrate solution on the substrate. From this point the substrate followed the method of preparing $\mathrm{TiO}_{2}$-based photoanodes as described in the photoanode preparation section.

\subsubsection{Graphite paste preparation}

The graphite paste of counter-electrode was prepared based on the method employed in the work of Wei and collaborators $^{29}$. To $5.0 \times 10^{-1} \mathrm{~g}$ of the graphite (Sigma-Aldrich), $5.0 \times 10^{-4} \mathrm{~L}$ of the $25 \% \mathrm{w} / \mathrm{w} \mathrm{TiO}_{2}$ commercial suspension (Sigma Aldrich, mean particle size $<50 \mathrm{~nm}$ ), $5.0 \times 10^{-4} \mathrm{~L}$ of Triton-100x (Vetec), and $1.0 \times 10^{-3}$ L of Milli-Q water were added. The resulting suspension was mixed with the aid of a spatula and then sonicated for 10 minutes.

\subsubsection{Counter-electrode preparation}

The counter electrodes were prepared using three different sources, two based on graphite and one on platinum. The first consisted of scratching the substrate with a $2 \mathrm{~B}$ pencil so that the graphite would be attached to the glass slide. The second form involving graphite consisted of a tape casting deposition of the graphite paste prepared via the method described in the Graphite paste preparation section. Depositions of $2.0 \times 10^{-5} \mathrm{~L}$ of the graphite paste were made and then the suspension was spread over the delimited area on the substrate using a microscope slide. After the film dried the process was repeated twice more, totaling three applications. After the last drying the counter electrode made from the graphite paste was sintered at 723 $\mathrm{K}$ for 30 minutes.

The last type of counter electrode fabricated consisted of a tape casting deposition of $0.50 \mathrm{~mol} \mathrm{~L}^{-1}$ solution of $\mathrm{H}_{2} \mathrm{PtCl}_{6} .4 \mathrm{H}_{2} \mathrm{O}$ (Merck) in $2.0 \times 10^{-5} \mathrm{~L}$ isopropyl alcohol (Vetec). After drying, the substrate containing the film was sintered at $673 \mathrm{~K}$ for 30 minutes to form a thin platinum film by thermal decomposition of $\mathrm{H}_{2} \mathrm{PtCl}_{6} \cdot 4 \mathrm{H}_{2} \mathrm{O}$.

$$
\mathrm{H}_{2} \mathrm{PtCl}_{6} \cdot 4 \mathrm{H}_{2} \mathrm{O}_{(1)} \rightarrow \mathrm{PtCl}_{4(\mathrm{~s})}+2 \mathrm{HCl}_{(1)}+4 \mathrm{H}_{2} \mathrm{O}_{(1)}
$$

$\mathrm{PtCl}_{4(\mathrm{~s})} \rightarrow \mathrm{Pt}_{(\mathrm{s})}+2 \mathrm{Cl}_{2(\mathrm{~g})}$

\subsubsection{Dye solution preparation}

The N3 dye solution was prepared by dissolving the ruthenium (II) cis-dithiocyanatobis (2,2'-bipyridine-4,4'dicarboxylate) (Sigma Aldrich) in $1.0 \times 10^{-2} \mathrm{~L}$ of ethanol PA (Vetec), yielding a solution with concentration $5.0 \times 10^{-4}$ mol L-1 in which the photoanodes were immersed.

\subsubsection{Liquid electrolyte preparation}

Liquid electrolytes were prepared by solubilizing the salts tetrabutylammonium iodide (Fluka), cesium iodide (Vetec), sodium iodide (Vetec) or potassium iodide (Vetec) in $5.0 \times 10^{-3} \mathrm{~L}$ of acetonitrile in order to have concentrations $0.05 \mathrm{~mol} \mathrm{~L}^{-1}(0.05 \mathrm{M})$ or $0.5 \mathrm{~mol} \mathrm{~L}^{-1}(0.5 \mathrm{M})$. In addition $\mathrm{I}_{2}$ (Sigma-Aldrich) was also solubilized in the liquid electrolyte either forming $5.0 \times 10^{-3} \mathrm{~mol} \mathrm{~L}^{-1}(0.005 \mathrm{M})$ or $0.05 \mathrm{~mol} \mathrm{~L}^{-1}$ $(0.05 \mathrm{M})$ solution. Some liquid electrolytes also included 4-tert-butylpyridine (Sigma-Aldrich) in $0.05 \mathrm{~mol} \mathrm{~L}^{-1}(0.05 \mathrm{M})$ or $0.5 \mathrm{~mol} \mathrm{~L}^{-1}(0.5 \mathrm{M})$ concentration.

\subsubsection{Solar cell build up}

After completion of photoanode and counter electrode preparation, the cell was assembled for electrochemical tests. The cells were assembled by placing one electrode displaced over the other, using a spacer between the substrates. The electrolyte was added to the photoanode before being covered by the counter electrode. A warm-up with a hot air blower is performed so that the spacer softens and joins the two substrates, sealing the cell.

With the values of $\boldsymbol{j}_{\mathbf{s c}}$ (short circuit current density), $\mathbf{V}_{\mathrm{oc}}$ (open circuit potential) and $\mathbf{P}_{\text {max }}$ (maximum power) solar cell performance can be expressed in terms of efficiency $(\eta)$ and fill factor $(\mathbf{F F})$. The fill factor is a power ratio that shows the relationship between the maximum power obtained and the maximum possible. It is obtained from the division between the maximum power displayed by the device and the product between $\boldsymbol{j}_{\mathbf{s c}}$ and $\mathbf{V}_{\mathbf{o c}}$, which also has power dimension (Equation 3).

$$
F F=\frac{P_{\max }}{J_{s c} \times V_{o c}}
$$

Efficiency $(\eta)$ is a parameter that measures the effectiveness of the device's conversion of solar to electrical energy. It is the main parameter to be compared between two different devices.

$\eta=\frac{J_{s c} \times V_{o c} \times F F}{P_{i n}}$

Being $\mathbf{P}_{\text {in }}$ the incident light power.

\section{Results and Discussion}

\subsection{Influence of the glass substrate}

The effect on solar cell performance of changing the substrate on which the semiconductor oxide is deposited was verified by producing two cells under the same conditions, one with both the anode and the counter electrode on ITO and the other on FTO. The results of the photovoltaic tests for these two cells are shown in Figure 1 and Table 1.

The difference of substrates appears during the making of the photovoltaic cell. When heated during the film sintering 
Table 1. $j$ x V curve results of cells with ITO and FTO.

\begin{tabular}{ccccc}
\hline Conducting glass & $\mathbf{V}_{\text {oc }}(\mathbf{V})$ & $\mathbf{j}_{\mathbf{s c}}\left(\mathbf{A} / \mathbf{c m}^{\mathbf{2}}\right)$ & Fill Factor $(\mathbf{\%})$ & $\boldsymbol{\eta}(\mathbf{\%})$ \\
\hline ITO cell & 0.728 & $2.026 \times 10^{-3}$ & 22.386 & 0.330 \\
\hline FTO cell & 0.738 & $2.439 \times 10^{-3}$ & 23.881 & 0.430 \\
\hline
\end{tabular}

Table 2. $j$ x V curve results of cells using pencil graphite as counter electrode.

\begin{tabular}{ccccc}
\hline Counter electrode & $\mathbf{V}_{\text {oc }}(\mathbf{V})$ & $\mathbf{j}_{\text {sc }}\left(\mathbf{A} / \mathbf{c m}^{2}\right)$ & Fill Factor $(\mathbf{\%})$ & $\boldsymbol{\eta}(\mathbf{\%})$ \\
\hline Sintered pencil graphite & 0.815 & $5.440 \times 10^{-4}$ & 24.369 & 0.108 \\
\hline Non-sintered pencil graphite & 0.691 & $1.514 \times 10^{-3}$ & 19.321 & 0.202 \\
\hline
\end{tabular}

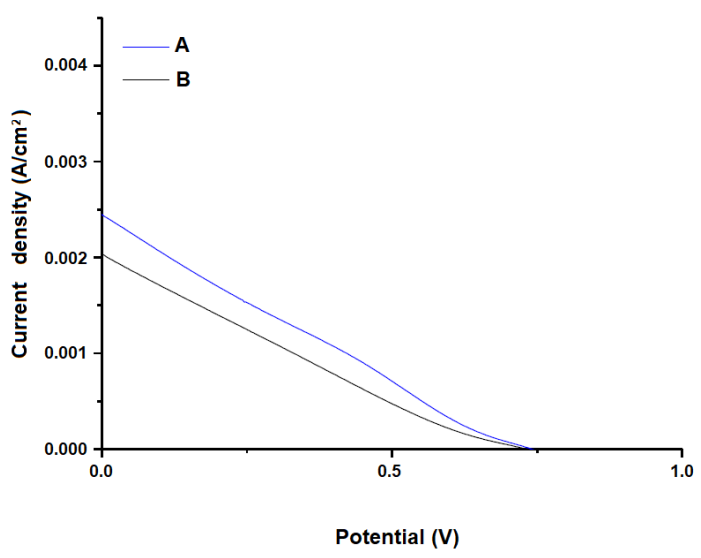

Figure 1. $j \mathrm{x}$ V curve of cells using FTO (A) and ITO (B) substrates. Other conditions: electrolyte: $\mathrm{KI}(0.05 \mathrm{M}) / \mathrm{I}_{2}(0.005 \mathrm{M})$ / 4-tert-butylpyridine ( $0.05 \mathrm{M})$; Counter electrode: Graphite paste; Photoanode: $\mathrm{TiO}_{2}$.

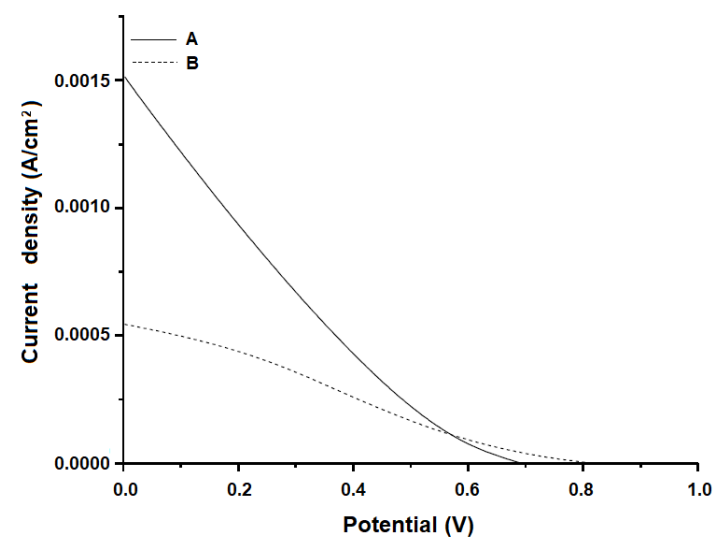

Figure 2. $j \times \mathrm{V}$ curves of cells using non-sintered (A) and sintered (B) graphite from a pencil. Other conditions: electrolyte: tetrabutylammonium iodide $(0.05 \mathrm{M}) / \mathrm{I}_{2}(0.005 \mathrm{M})$; substrate: ITO; Photoanode: $\mathrm{TiO}_{2}$.

process, the ITO undergoes an increase in resistivity that is credited to the bond that atmospheric oxygen forms with the network, decreasing the number of carriers, which increases the resistivity. Increased resistivity leads to poorer cell performance using this substrate and it is an irreversible change, not allowing reuse of the substrate in new cells. In contrast, the FTO has a stable resistivity when subjected to heating and can be reused if properly cleaned and if not attacked by any component of the cell.

\subsection{Influence of the counter-electrode}

The graphite counter electrode is an alternative to platinum, which is usually used in these cells, having as advantages the large surface area and being a cheaper option. In addition to the preparation of graphite counter electrodes based on the work of Wei et al. ${ }^{29}$, the use of a $2 \mathrm{~B}$ pencil as a source of graphite counter electrode was tested. As can be seen in Figure 2, the counter electrodes made from pencil graphite were able to have photovoltaic effect, both with and without the sintering step, reinforcing the low-cost character of the device that can even be applied as a demonstrative material in experimental classes.

The results in Table 2 reveal that the device whose counter electrode has not gone through the sintering process presents better performance, evidenced by the higher short circuit current and efficiency. However, it was not possible to perform the same test with the graphite paste-based counter electrode, because the sintering step is essential for the film to be adhered to the substrate, so only the comparison with the device undergoing the sintering process was performed (Figure 3). Comparison between graphite deposition methods shows that graphite paste exhibits better performance and greater control over its composition compared to sintered graphite deposited from a pencil (Table 3 ).

Finally a comparison was made between the counter electrodes obtained from the graphite paste with the counter electrodes of the platinum. From the data in Figure 4 and Table 4 it is possible to verify that the platinum counter electrode presents a better performance compared to graphite, mainly regarding the fill factor. Its good performance can be credited to platinum's ease in catalyzing the iodide / triiodide pair reduction reaction.

The superior performance of the platinum counter electrode is evident when looking at its $\boldsymbol{j} \mathbf{x} \mathbf{V}$ curve (Figure 4), which has the characteristic shape of this type of device, resulting in the highest fill factor. Despite the difference in performance, the device containing the counter electrode made from graphite paste exhibits good results, thus being a viable option and a way to reduce the cost of this type of device. At last, the superior performance of graphite electrode in Table 4 in face of the results of Table 3 can be explained due to the use of 4-tert-butylpiridine in the electrolyte which will be properly addressed in a later section of the present manuscript.

\subsection{Influence of the anodic electrode}

The anodic part of DSSC was then studied regarding the use of Au shottky barriers in order to disable the recombination of electrons. First the microstructure of the $\mathrm{TiO}_{2}$ film was visualized using SEM images (Figure 5 left). It can be seen 
Table 3. $j$ x V curve results of cells using pencil graphite and graphite paste as counter electrode.

\begin{tabular}{ccccc}
\hline Counter electrode & $\mathbf{V}_{\text {oc }}(\mathbf{V})$ & $\mathbf{j}_{\text {sc }}\left(\mathbf{A} / \mathbf{c m}^{2}\right)$ & Fill Factor $\mathbf{( \% )}$ & $\boldsymbol{\eta}(\mathbf{\%})$ \\
\hline Graphite paste $\mathbf{( 7 2 3 ~ K )}$ & 0.774 & $9.391 \times 10^{-4}$ & 27.739 & 0.202 \\
\hline Pencil graphite (723 K) & 0.815 & $5.440 \times 10^{-4}$ & 24.369 & 0.108 \\
\hline
\end{tabular}

Table 4. $j \mathrm{x}$ V curve results of cells using platinum and graphite paste electrode.

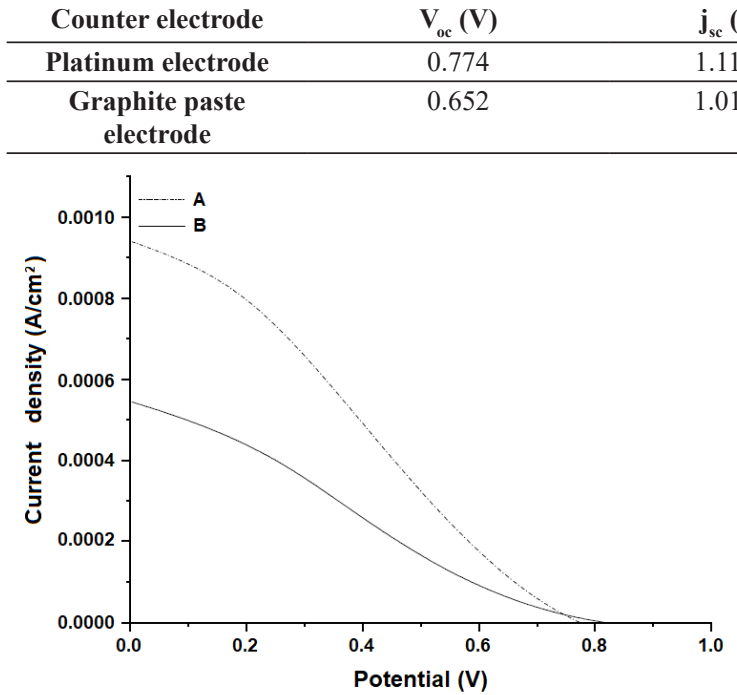

Figure 3. $j \mathrm{x}$ V curves of cells with two different forms of graphite deposition from graphite paste (A) and pencil (B), both sintered at $723 \mathrm{~K}$. Other conditions: electrolyte: tetrabutylammonium iodide $(0.05 \mathrm{M}) / \mathrm{I}_{2}(0.005 \mathrm{M})$; substrate: FTO; Photoanode: $\mathrm{TiO}_{2}$.

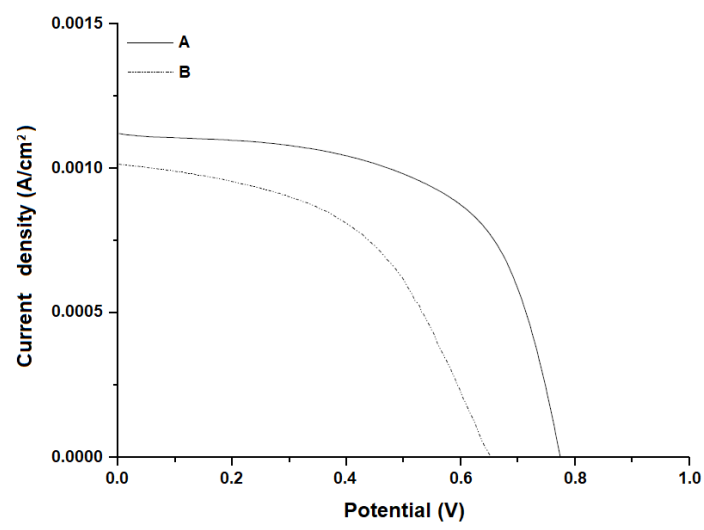

Figure 4. $j \mathrm{x}$ V curves resulting from cells employing platinum (A) and graphite (B) electrodes. Other conditions: electrolyte: tetrabutylammonium iodide $(0.05 \mathrm{M}) / \mathrm{I}_{2}(0.005 \mathrm{M}) / 4$-tert-butylpyridine; substrate: FTO; Photoanode: $\mathrm{TiO}_{2}$.

a dense microstructure of a $10 \mu \mathrm{m}$ thick film. Figure 5 right image shows the visualization via backscattered electrons of $\mathrm{TiO}_{2}$ film with gold nanoparticles on the surface, deposited via wet impregnation method. Gold is visualized as brilliant spots, appearing as agglomerates after heating.

Concerning anode performance gold nanoparticles supported on $\mathrm{TiO}_{2}$ prepared by the wet impregnation method were analyzed by TGA to determine the required calcination temperature for the citrate to be removed from the photoanode. From the results obtained (Figure 6) it can be seen that titanium presents a progressive loss of mass with the heating, product of the dehydroxylation of its surface; in turn the sample containing the gold nanoparticles presents a sudden mass loss from the heating at $503 \mathrm{~K}$, which may be attributed to the citrate volatization from the sample. The mass losses collected from the TG analysis are summarized in Table 5.

From data summarized in Table 5, in the $373-623 \mathrm{~K}$ range there is a significant mass loss due to the presence of citrate in the $\mathrm{TiO}_{2}+$ AuNP sample; in other temperature ranges analyzed the loss on heating is similar for both samples. Therefore, photoanode when heated up to $723 \mathrm{~K}$ during cell preparation would already be free of citrate.

Inspecting again the TGA-DTA curves of Figure 5 it can be noticed that from $693 \mathrm{~K}$ the curve referring to the thermodifferential analysis diverges in the two samples, revealing that in the sample containing the gold nanoparticles there is a thermal event that does not appear in the pure titania sample: this phenomenon is then related solely to gold nanoparticles. By the end of thermogravimetric analysis it was found there was a visual change in the samples containing the gold nanoparticles after heating, Figure 7.

Visual change is reflected in data obtained from ultravioletvisible diffuse reflectance spectroscopy. Spectra obtained for the powders containing unheated gold nanoparticles and heated to $723 \mathrm{~K}$ and $1,073 \mathrm{~K}$ are shown in Figure 8. It is possible to observe in the case of the $1,073 \mathrm{~K}$ calcined sample the displacement of the absorption band for longer wavelengths. (red shift): this band refers to the resonance of gold nanoparticle plasmons ${ }^{30}$. The displacement is linked to the size of the nanoparticles on the surface of the titania, in this case the nanoparticles present in the $1,073 \mathrm{~K}$ calcined sample are larger than those that were not heated or were heated to only $723 \mathrm{~K}$.

Comparing these results with the data obtained from the thermo-differential analysis it is possible to state that this nanoparticle growth process takes place from $693 \mathrm{~K}$ but does not show appreciable change in the sample calcined at $723 \mathrm{~K}$ to be detected by the ultraviolet-visible diffuse reflectance spectroscopy.

This change in gold nanoparticles could lead to differentiated photovoltaic behavior of the device. To check this, three cells were assembled: one with pure $\mathrm{TiO}_{2}$ and two with $\mathrm{TiO}_{2}$ containing gold nanoparticles, one without preheating and the other with the previous calcination of the powder at 1,073 $\mathrm{K}$ : the other parameters were equal for proper comparison of the cell. It must be kept in mind that all these photoanodes were tested after being sintered at $723 \mathrm{~K}$. The result of the photovoltaic behavior can be seen in Figure 9 and the data in Table 6. The use of gold nanoparticles did not represent 
Table 5. Mass loss data obtained from thermogravimetric analysis for pure and gold nanoparticle $\mathrm{TiO}_{2}$ with or without gold nanoparticles (AuNPs).

\begin{tabular}{cccc}
\hline Sample & Considered range (K) & Weight loss (\%) & Total weight loss (\%) \\
\cline { 2 - 3 } TiO $_{2}$ & $298-373$ & & \multirow{2}{*}{6.25} \\
\cline { 2 - 3 } & $373-623$ & 2.14 & \\
\cline { 2 - 3 } TiO $_{2}+$ AuNPs & $623-1,073$ & 2.60 \\
\cline { 2 - 4 } & $298-373$ & 1.67 & \multirow{2}{*}{8.08} \\
\hline
\end{tabular}

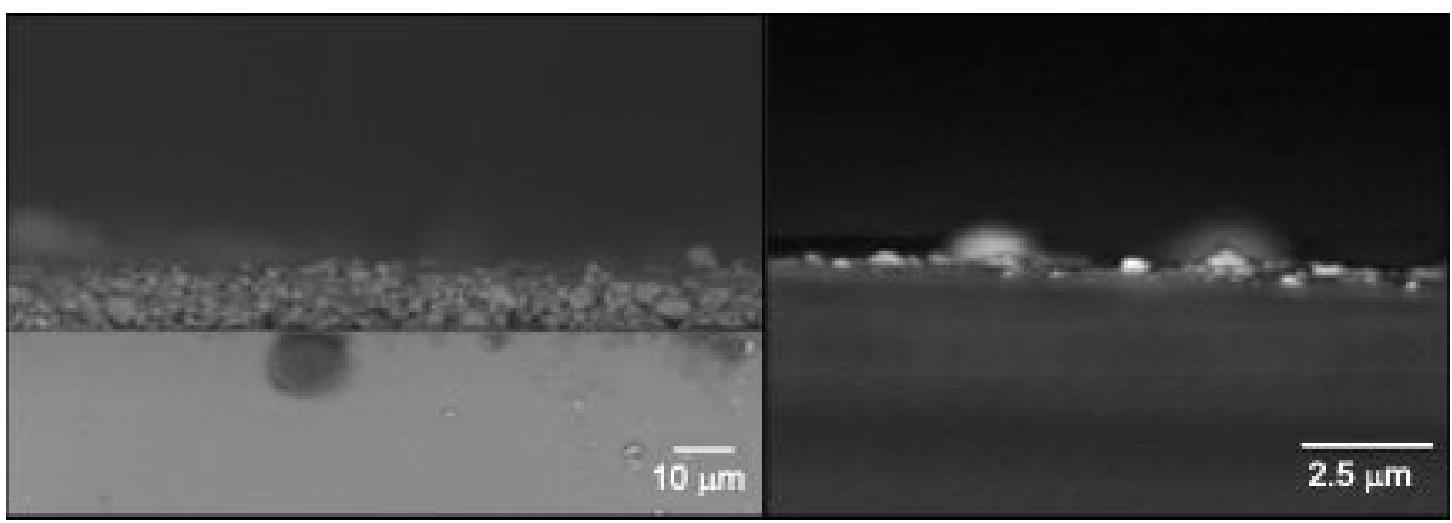

Figure 5. SEM visualizations: secondary electrons image of $\mathrm{TiO}_{2}$ film with $1,000 \mathrm{X}$ magnification (left); and backscattered electrons image of $\mathrm{Au} / \mathrm{TiO}_{2}$ filme with 10,000 X magnification (right).
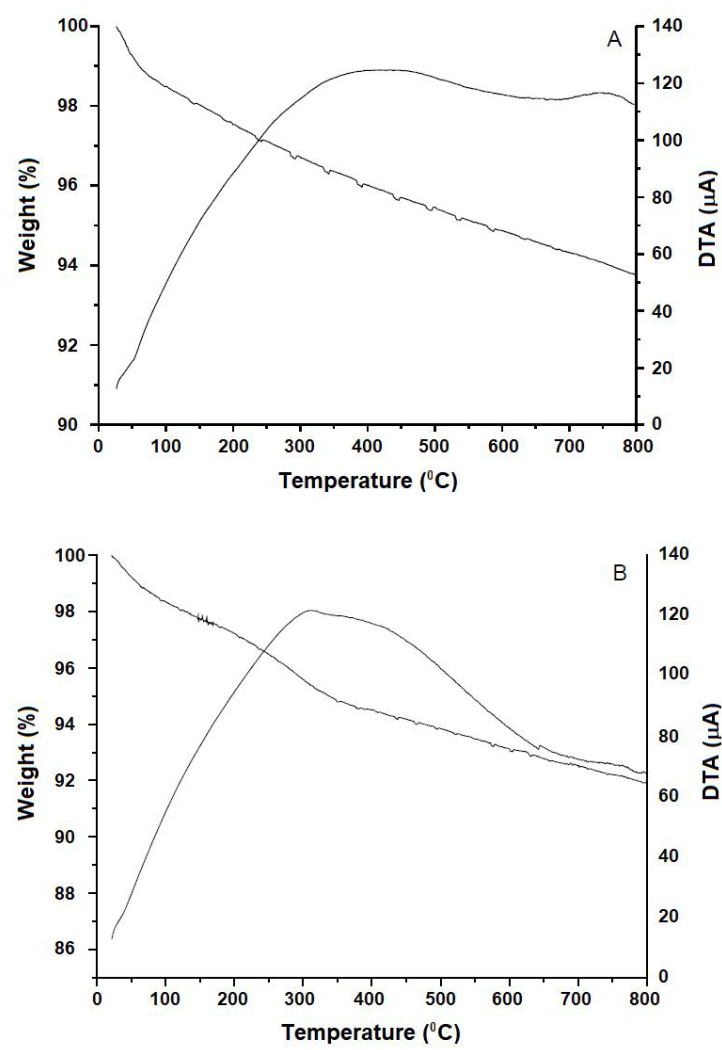

Figure 6. Thermogravimetric (full line) and thermodifferential analysis (segmented line) of pure (A) and gold nanoparticleimpregnated $\mathrm{TiO}_{2}(\mathrm{~B})$.

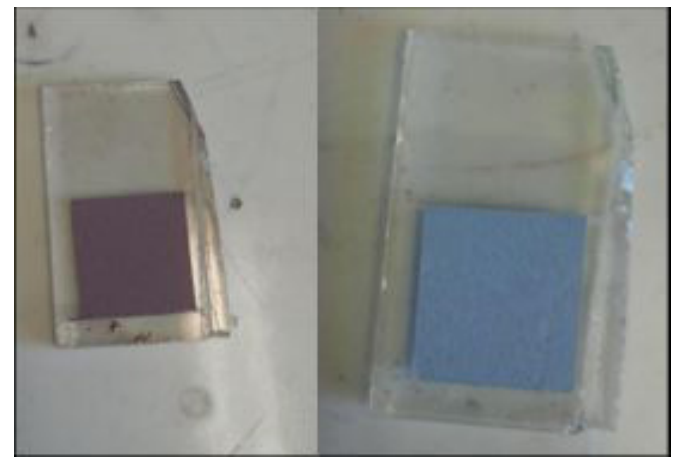

Figure 7. Films made from $\mathrm{TiO}_{2}$ powders with gold nanoparticles, without heating (left) and heating at 1,073 K (right).

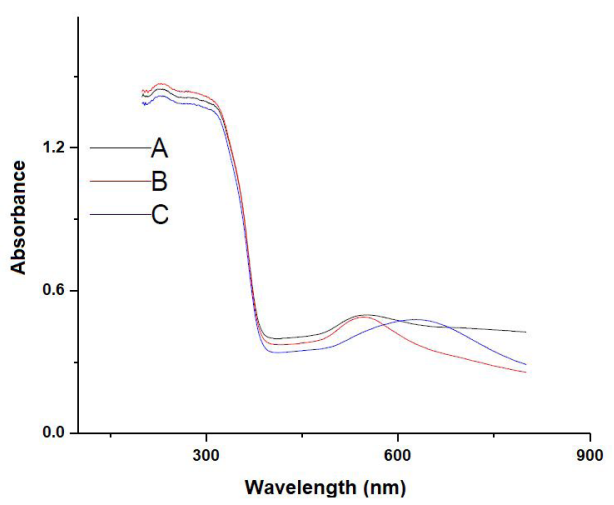

Figure 8. Visible-ultraviolet diffuse reflectance spectra for $\mathrm{TiO}_{2}$ with AuNPs without heating(A); $\mathrm{TiO}_{2}$ with AuNPs heated up to $723 \mathrm{~K}$ (B) and $\mathrm{TiO}_{2}$ with AuNPs heated up to $1,073 \mathrm{~K}$ (C). 
an improvement of the system: the performances of cells with pure $\mathrm{TiO}_{2}$ and nanoparticles without heating were very similar, whereas the device containing the nanoparticles that were heated up to $1,073 \mathrm{~K}$ underperformed the previous two.

The $\mathrm{TiO}_{2} /$ AuNPs materials were analyzed by X-ray diffraction to check for any other factors that could explain the unfavorable behavior of the $1,073 \mathrm{~K}$ calcined sample. From the diffractograms shown in Figure S1 (Supplementary material), the red arrows show diffraction peaks occurring in the sample calcined at $1,073 \mathrm{~K}$, in contrast to the non-calcined sample. These peaks could be related to the nanoparticle growth or second phase formation. Via Crystmet database the crystallographic data of the $\mathrm{TiO}_{2}$ in the rutile and anatase phases (cards \#137291 and 497154, respectively) were plotted against the XRD pattern of $\mathrm{TiO}_{2} / \mathrm{AuNPs}$ heated up to $1,073 \mathrm{~K}$, Figure S2 (Supplementary material). It can be concluded that there is a $\mathrm{TiO}_{2}$ phase transition with heating up to high temperatures, so that a direct comparison among cells cannot be made.

The quantification of nanoparticles deposited in titania via wet impregnation could not be determined by in-solution ultraviolet-visible absorption spectroscopy due to the reminiscence of suspended titanium oxide even after intense centrifugation. This justified the use of the second method of immobilizing the nanoparticles, with solvent evaporation: all dispersed nanoparticles in the solvent would be deposited on the titania. The third impregnation method aims at the formation of nanoparticles in situ on titania; again, it is not simple to measure the amount of gold nanoparticles over $\mathrm{TiO}_{2}$.

The different $\mathrm{Au}$ impregnation methods (wet, intimate and solvent evaporation approaches) were compared by testing the photovoltaic behaviors of the respective solar cell devices. These data are shown in Figure 10 and in Table 7.

The results reveal that the type of impregnation influences the device performance. The highest efficiencies were obtained by the samples of pure titania and titania wet impregnated with gold nanoparticles, with a small difference in performance between the two. Among the impregnation methods, the best results were those from wet impregnation. Hopefully impregnation via solvent evaporation would result in a greater amount of gold nanoparticles deposited over titania; however, it actually presented the worst efficiency results, possibly due to the agglomeration of gold nanoparticles that can occur after solvent evaporation.

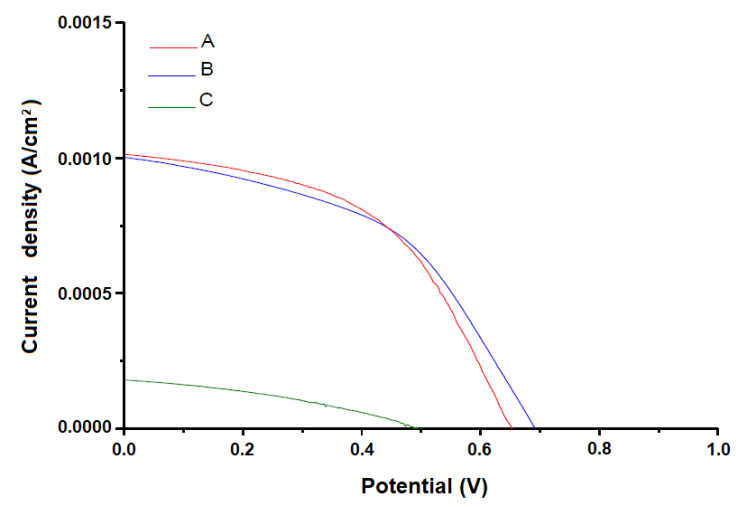

Figure 9. $j \mathrm{x}$ V curve for photoanodes employing pure $\mathrm{TiO}_{2}(\mathrm{~A})$ with gold nanoparticles (B) and 1,073 K calcined gold nanoparticles (C). Other conditions: electrolyte: tetrabutylammonium iodide $(0.05 \mathrm{M}) / \mathrm{I}_{2}(0.005 \mathrm{M}) / 4$-tert-butylpyridine; substrate: FTO; counter electrode: graphite paste.

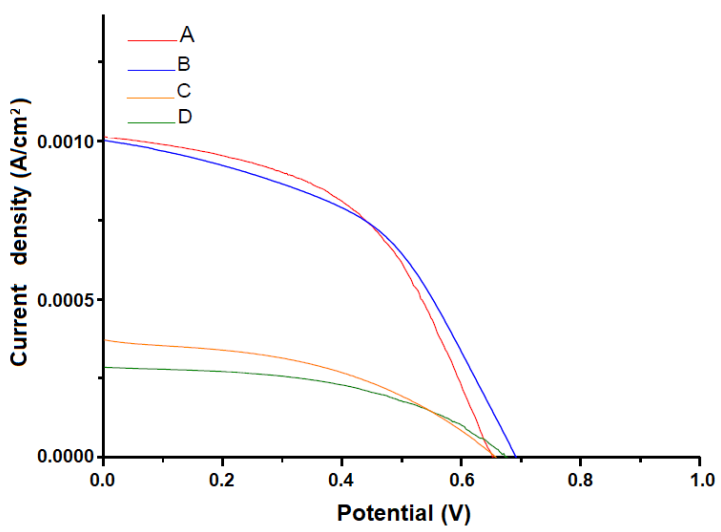

Figure 10. $j \mathrm{x}$ V curves applying pure $\mathrm{TiO}_{2}(\mathrm{~A})$ and $\mathrm{TiO}_{2}$ support for $\mathrm{Au}$ by wet impregnation (B), intimate (C) and evaporative (D) approach as photoanodes. Other conditions: electrolyte: tetrabutylammonium iodide $(0.05 \mathrm{M}) / \mathrm{I}_{2}(0.005 \mathrm{M})$ / 4-tert-butylpyridine; FTO substrate; counter-electrode: graphite paste.

Table 6. $j$ x V curve results of $\mathrm{TiO}_{2}$ cells with or without gold nanoparticles via wet impregnation.

\begin{tabular}{ccccc}
\hline Photoanode & $\mathbf{V}_{\text {oc }}(\mathbf{V})$ & $\mathbf{j}_{\text {sc }}\left(\mathbf{A} / \mathbf{c m}^{\mathbf{2}}\right)$ & Fill Factor (\%) & $\boldsymbol{\eta}(\mathbf{\%})$ \\
\hline $\mathbf{T i O}_{2}$ & 0.652 & $1.014 \times 10^{-3}$ & 49.957 & 0.330 \\
\hline $\mathrm{TiO}_{2}+$ AuNPs & 0.691 & $1.001 \times 10^{-3}$ & 47.890 & 0.331 \\
\hline $\mathbf{T i O}_{2}+$ AuNPs (calcination at $\mathbf{1 , 0 7 3 ~ K )}$ & 0.493 & $1.796 \times 10^{-4}$ & 35.493 & 0.031 \\
\hline
\end{tabular}

Table 7. $j \mathrm{x}$ V curve results of cells with Au nanoparticles supported via different impregnation methods.

\begin{tabular}{cllll}
\hline Photoanode & $\mathbf{V}_{\text {oc }}(\mathbf{V})$ & $\mathbf{j}_{\mathbf{s c}}\left(\mathbf{A} / \mathbf{c m}^{2}\right)$ & Fill Factor $(\mathbf{\%})$ & $\boldsymbol{\eta}(\mathbf{\%})$ \\
\hline $\mathbf{T i O}_{2}$ & 0.652 & $1.014 \times 10^{-3}$ & 49.952 & 0.330 \\
\hline Wet impregnation & 0.691 & $1.000 \times 10^{-3}$ & 47.890 & 0.331 \\
\hline Evaporative impregnation & 0.674 & $2.628 \times 10^{-4}$ & 48.560 & 0.086 \\
\hline Intimate impregnation & 0.657 & $3.714 \times 10^{-4}$ & 44.087 & 0.108 \\
\hline
\end{tabular}




\subsection{Influence of the electrolyte composition}

The electrolyte components were investigated to verify how the electrochemical behavior would be modified. The use of additives such as 4-tert-butylpyridine increases cell efficiency, causing an increase in open circuit potential, as shown in Figure 11 and Table 8.

The effect of 4-tert-butylpyridine is credited to the adsorption of this additive at uncovered semiconductor sites, thereby reducing electron recombination processes between the electrolyte and the semiconductor ${ }^{31}$. 4-tert-Butylpyridine also increases $\mathrm{TiO}_{2}$ conduction band to higher energies, thereby increasing the $\mathrm{V}_{\mathrm{oc}}$.

Electrolyte counter ions to iodide were also varied to verify how the electrochemical behavior of the device would be modified (Figures 12 and 13; and Tables 9 and 10). The counter ions evaluated were tetrabutylammonium, sodium, potassium and cesium. The nature of the counter ion affects the electrochemical behavior, as can be seen from the $\boldsymbol{j} \mathbf{x}$ $\mathbf{V}$ curves of Figures 12 and 13, so that electrolytes whose cations are the smallest in the series $\mathrm{Na}, \mathrm{K}$ and $\mathrm{Cs}$ allow obtaining higher efficiencies (Table 9 and 10).

In addition to the screening of the counter ions, the concentration of the electrolyte constituents was also changed, keeping the same molar proportion among them, Figure 13 and Table 10. The data (Tables 9 and 10) show that generally decreasing component concentration leads to a decrease in device efficiency, decreasing fill factor and open circuit potential. However, KI and CsI-based devices had their currents increased when they employed diluted electrolytes. The change of triiodide ion mobility in electrolyte solutions would be the cause for different efficiencies observed by varying iodide counter ion. According to the work of Liu et al. ${ }^{32}$ the largest the cation is the least solvated it becomes what would make it interact with the triiodide reducing its activity and mobility.

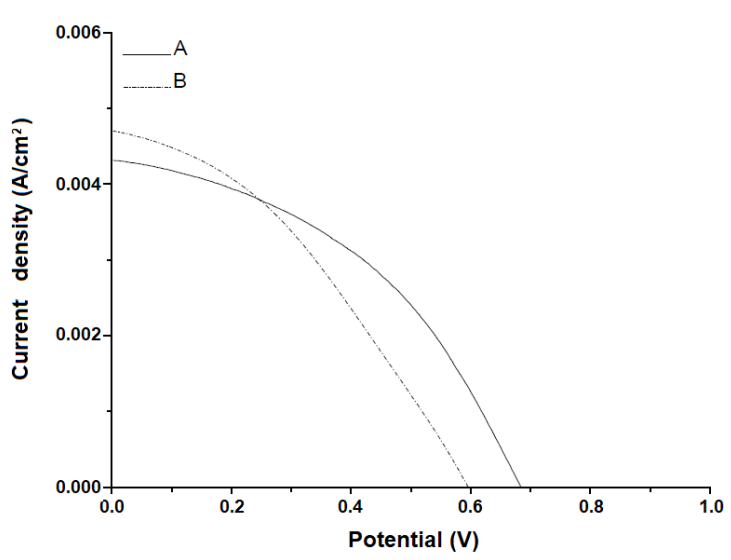

Figure 11. $j \times \mathrm{V}$ curve for cells with (A) and without (B) 4-tertbutylpyridine $(0.05 \mathrm{M})$. Electrolyte: $\mathrm{NaI}(0.5 \mathrm{M})$ / I2 $(0.05 \mathrm{M})$. Other conditions: FTO; counter- electrode: graphite paste; Photoanode: $\mathrm{TiO}_{2}$.

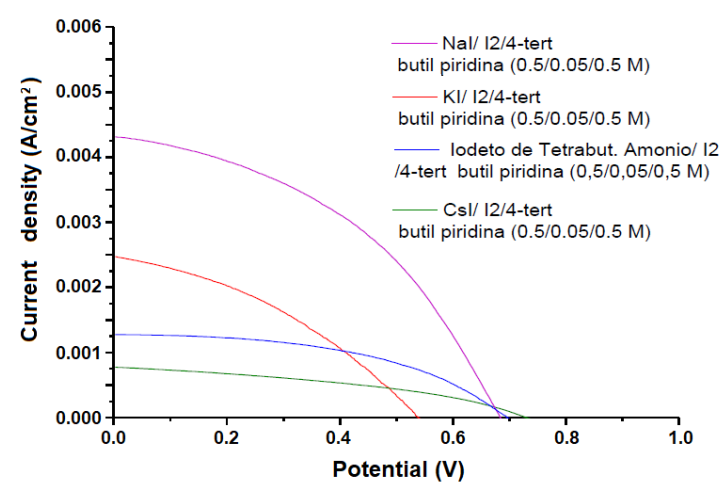

Figure 12. $j \mathrm{x} \mathrm{V}$ curve for cells screening counter-ions to iodide in electrolyte solutions. Other conditions: FTO; counter electrode: graphite paste; Photoanode: $\mathrm{TiO}_{2}$.

Table 8. $j \mathrm{x}$ V curve results of cells employing or not 4-tert-butylpiridine in the electrolyte.

\begin{tabular}{ccccc}
\hline Electrolyte & $\mathbf{V}_{\text {oc }}(\mathbf{V})$ & $\mathbf{j}_{\text {sc }}\left(\mathbf{A} / \mathbf{c m}^{2}\right)$ & Fill Factor (\%) & $\boldsymbol{\eta}(\%)$ \\
\hline $\mathbf{N a I} / \mathbf{I}_{\mathbf{2}} /$ 4-tert-butylpyridine $\left.\mathbf{( 0 . 5 M} / \mathbf{0 . 0 5 M} / \mathbf{0 . 5 M}\right)$ & 0.684 & $4.314 \times 10^{-3}$ & 42.917 & 1.265 \\
\hline $\left.\mathrm{NaI} / \mathbf{I}_{\mathbf{2}} \mathbf{( 0 . 5 M} / \mathbf{0 . 0 5 M}\right)$ & 0.596 & $4.699 \times 10^{-3}$ & 36.595 & 1.024 \\
\hline
\end{tabular}

Table 9. $j \mathrm{x}$ V curve results of cells tested varying the iodide counter-ion in the electrolyte composition.

\begin{tabular}{|c|c|c|c|c|}
\hline Electrolyte & $\mathbf{V}_{\mathrm{oc}}(\mathrm{V})$ & $\mathrm{j}_{\mathrm{sc}}\left(\mathrm{A} / \mathrm{cm}^{2}\right)$ & Fill Factor $(\%)$ & $\eta(\%)$ \\
\hline $\mathrm{NaI} / \mathrm{I}_{2} /$ 4-tert-butylpyridine (0.5M / 0.05M / 0.5M) & 0.684 & $4.314 \times 10^{-3}$ & 42.917 & 1.265 \\
\hline KI / I / 4-tert-butylpyridine (0.5M / 0.05M / 0.5M) & 0.537 & $2.473 \times 10^{-3}$ & 36.784 & 0.489 \\
\hline CsI / $\mathrm{I}_{2} /$ 4-tert-butylpyridine (0.5M / 0.05M / 0.5M) & 0.728 & $7.731 \times 10^{-4}$ & 39.246 & 0.221 \\
\hline Tetrabutylammonium iodide / $\mathrm{I}_{2}$ / 4-tert-butylpyridine $(0.5 \mathrm{M} / \mathrm{0.05M} / 0.5 \mathrm{M})$ & 0.696 & $1.276 \times 10^{-3}$ & 48.211 & 0.428 \\
\hline
\end{tabular}

Table 10. $j$ x V curve results of cells tested varying the iodide conter-ion in the electrolyte composition, less concentrated solutions.

\begin{tabular}{|c|c|c|c|c|}
\hline Electrolyte & $V_{o c}(V)$ & $\mathbf{j}_{\mathrm{sc}}\left(\mathbf{A} / \mathbf{c m}^{2}\right)$ & $\begin{array}{c}\text { Fill Factor } \\
(\%)\end{array}$ & $\eta(\%)$ \\
\hline $\mathrm{NaI} / \mathrm{I}_{2} /$ 4-tert-butylpyridine $(0.05 \mathrm{M} / 0.005 \mathrm{M} / 0.05 \mathrm{M})$ & 0.621 & $4.419 \times 10^{-3}$ & 33.026 & 0.905 \\
\hline KI / I / 4-tert-butylpyridine (0.05M / 0.005M / 0.05M) & 0.457 & $5.852 \times 10^{-3}$ & 32.484 & 0.868 \\
\hline CsI / I / 4-tert-butylpyridine (0.05M / 0.005M / 0.05M) & 0.503 & $2.224 \times 10^{-3}$ & 25.833 & 0.289 \\
\hline Tetrabutylammonium iodide / $\mathrm{I}_{2}$ / 4-tert-butylpyridine $(0.05 \mathrm{M}$ / 0.005M / 0.05M) & 0.652 & $1.014 \times 10^{-3}$ & 49.957 & 0.330 \\
\hline
\end{tabular}




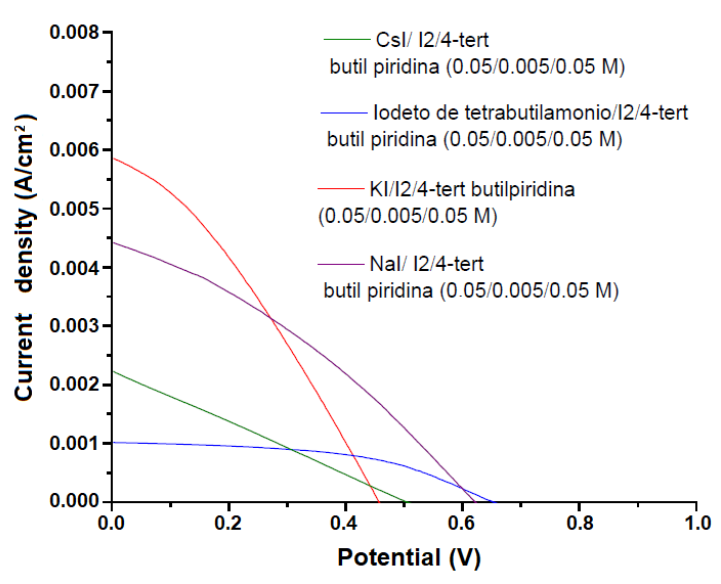

Figure 13. $j \mathrm{x}$ V curve for cells screening counter-ions to iodide in less concentrated electrolyte solutions. Other conditions: Substrate: FTO; counter electrode: graphite paste; Photoanode: $\mathrm{TiO}_{2}$.

\section{Conclusions}

The present work reported the set of conditions for the best performance of dye-sensitized solar cells. With respect to the counter-electrode, the substitution of platinum for graphite still permitted to obtain quite good results keeping the low cost of the device. Concerning the photoanode the use of gold nanoparticles over titania did not bring a device improvement, since in some cases this impregnation, although improving the electronic structure avoiding recombination phenomenon, blocks the Ti sites from binding the dye molecule. This is factual for some $\mathrm{Au}$ impregnation methods tested herein to which $0.1 \%$ efficiencies were obtained. The prior calcination of $\mathrm{Au} / \mathrm{TiO}_{2}$ powder at $1,073 \mathrm{~K}$ before film sintering generated an optical change for AuNPs (from red to blue); however it did worsen cell operation since rutile phase of $\mathrm{TiO}_{2}$ became predominant. Regarding the electrolyte solution the counter-ion to triiodide is an important variable to take into consideration since small cations as $\mathrm{Na}$ and $\mathrm{K}$ afforded the greatest values of efficiency and short-circuit current density. The use of one of these cations, sodium, together with 4-tert-butylpyridine enabled the best performance of DSSC that in the present work corresponded to $1.26 \%$ efficiency. This result was obtained using FTO glass, pure titanium dioxide with $\mathrm{N} 3$ sensitizing dye as photoanode, $\mathrm{NaI}\left(0.5 \mathrm{~mol} \mathrm{~L}^{-1}\right) / \mathrm{I}_{2}(0.05$ mol L-1) / 4-tert-butylpiridine $\left(0.5 \mathrm{~mol} \mathrm{~L}^{-1}\right)$ in acetonitrile as electrolyte and graphite as counter-electrode. Here one inconsistency may have arisen from the fact that platinum gave the best result when compared to graphite as counterelectrode $(0.543 \%$ versus $0.330 \%$ efficiency) but still the best result of the work was obtained from one cell employing graphite. When both counter-electrodes were compared by DSSC operation the other cell conditions had not yet been optimized. Therefore, this result of $1.26 \%$ can be improved by using Pt; however, there must be awareness that the use of such noble expensive metal not only increases the cost of DSSC construction (or acquisition) but also adds a recycling step to the disposal of DSSCs after their peak activity. This contradicts the expectation for a low-cost device for energy generation from renewable power sources.

\section{Acknowledgements}

The authors would like to thank CAPES, CNPq and FAPERJ for funding specifically FAPERJ project E-26/111.776/2011. One of the authors (LFBMalta) expresses gratitude for funding from FAPERJ (APQ1 project E-26/111.374/2014) and CNPq (Universal project 425613/2016-0)

\section{References}

1. Wang K, Liu C, Meng T, Yi C, Gong X. Inverted organic photovoltaic cells. Chemical Society Reviews. 2016;45(1021):2937-2975

2. Service RF. Is it time to shoot for the sun? Science. 2005;309(5734):548-51.

3. O'Regan B, Grätzel M. A low-cost, high efficiency solar cell based on dye-sensitized colloidal TiO2 films. Nature. 1991;353:737-40.

4. National Renewable Energy Laboratory - NREL [Internet]. Swiss scientists power past solar efficiency records. USA: National Renewable Energy Laboratory NREL; 2017 [cited 2019 Nov 25]. Available from: https://www.nrel.gov/news/press/2017/ swiss-scientists-power-past-solar-efficiency-records.html

5. Ye M, Wen X, Wang M, Iocozzia J, Zhang N, Lin C, et al. Recent advances in dye-sensitized solar cells: from photoanodes, sensitizers and electrolytes to counter electrodes. Mater Today. 2015;18(3):155-62.

6. Lv M, Zheng D, Ye M, Xiao J, Guo W, Lai Y, et al. Optimized porous rutile $\mathrm{TiO} 2$ nanorod arrays for enhancing the efficiency of dye-sensitized solar cells. Energy Environ Sci. 2013;6(5):161522.

7. Kim KH, Utashiro K, Abe Y, Kawamura M. Structural properties of zinc oxide nanorods grown on Al-doped zinc oxide seed layer and their applications in dye-sensitized solar cells. Materials (Basel). 2014;7(4):2522-33.

8. Ye M, Zheng D, Lv M, Lin C, Lin Z. Hierarchically structured nanotubes for highly efficient dye-sensitized solar cells. Adv Mater. 2013;25(22):3039-44.

9. Shi Y, Zhu C, Wang L, Li W, Fung KK, Wang N. Asymmetric ZnO panel-like hierarchical architectures with highly interconnected pathways for free-electron transport and photovoltaic improvements. Chemistry - A Europen Journal. 2012;19(1):282-87.

10. Siwatch S, Kundu VS, Kumar A, Kumar S, Chauhan N, Kumari M. Morphology correlated efficiency of $\mathrm{ZnO}$ photoanode in dye sensitized solar cell. Materials Research Express. 2019;6(10):1050d3.

11. Nien YH, Chen HH, Hsu HH, Kuo PY, Chou JC, Lai CH, et al. Enhanced photovoltaic conversion efficiency in dye-sensitized solar cells based on photoanode consisting of $\mathrm{TiO} 2 / \mathrm{GO} / \mathrm{Ag}$ nanofibers. Vacuum. 2019;167:47-53.

12. Zainudin SNF, Abdullah H, Markom M. Electrochemical studies of tin oxide based-dye-sensitized solar cells (DSSC): a review. J Mater Sci Mater Electron. 2019;30(6):5342-56.

13. Roh J, Hwang SH, Jang J. Dual-functional CeO2:Eu3+ nanocrystals for performance-enhanced dye-sensitized solar cells. Applied Materials \& Interfaces. 2014;6(22):19825-32.

14. Yu H, Bai Y, Zong X, Tang F, Max Lu GQM, Wang L. Cubic $\mathrm{CeO} 2$ nanoparticles as mirror-like scattering layers for efficient light harvesting in dye-sensitized solar cells. Chem Commun. 2012;48(59):7386-8.

15. Kim JH, Jang J, Kim SC, Han CH. Nanocrystalline antimony oxide films for dye-sensitized solar cell applications. Bull Korean Chem Soc. 2012;33(4):1204-8.

16. Muduli S, Game O, Dhas V, Vijayamohanan K, Bogle KA, Valanoor N, et al. TiO2-Au plasmonic nanocomposite for enhanced dye-sensitized solar cell (DSSC) performance. Sol Energy. 2012;86(5):1428-34. 
17. Wang Q, Butburee T, Wu X, Chen H, Liu G, Wang L. Enhanced performance of dye-sensitized solar cells by doping $\mathrm{Au}$ nanoparticles into photoanodes: a size effect study. J Mater Chem A Mater Energy Sustain. 2013;1(43):13524-31.

18. Ghaffari M, Burak Cosar M, Yavuz HI, Ozenbas M, Okyay AK. Effect of Au nano-particles on $\mathrm{TiO} 2$ nanorod electrode in dye-sensitized solar cells. Electrochim Acta. 2012;76:446-52.

19. Ali AK, Erten-Ela S, Hassoon KI, Ela C. Plasmonic enhancement as selective scattering of gold nanoparticles based dye sensitized solar cells. Thin Solid Films. 2019;671:127-32.

20. Han L, Islam A, Chen H, Malapaka C, Chiranjeevi B, Zhang $\mathrm{S}$, et al. High-efficiency dye-sensitized solar cell with a novel co-adsorbent. Energy Environ Sci. 2012;5(3):6057-60.

21. Al-Alwani MAM, Hasan HA, Al-Shorgani NKN, Al-Mashaan ABSA. Natural dye extracted from Areca catechu fruits as a new sensitiser for dye-sensitised solar cell fabrication: optimisation using D-Optimal design. Mater Chem Phys. 2020;240(15):122204.

22. Yella A, Mai CL, Zakeeruddin SM, Chang SN, Hsieh $\mathrm{CH}$, Yeh CY, et al. Molecular engineering of push-pull porphyrin dyes for highly efficient dye-sensitized solar cells: the role of benzene spacers. Angew Chem Int Ed. 2014;53(11):2973-7.

23. Mathew S, Yella A, Gao P, Humphry-Baker R, Curchod BFE, Ashari-Astani N, et al. Dye-sensitized solar cells with $13 \%$ efficiency achieved through the molecular engineering of porphyrin sensitizers. Nat Chem. 2014;6:242-7.
24. Min H, Kim M, Lee SU, Kim H, Kim G, Choi K, et al. Efficient, stable solar cells by using inherent bandgap of $\alpha$-phase formamidinium lead iodide. Science. 2019;366(6466):749-53.

25. Grätzel M. The light and shade of perovskite solar cells. Nat Mater. 2014;13:838-42.

26. Ke W, Kanatzidis MG. Prospects for low-toxicity lead-free perovskite solar cells. Nat Commun. 2019;10:965.

27. Liu Y, Male KB, Bouvrette P, Luong JHT. Control of the size and distribution of gold nanoparticles by unmodified cyclodextrins. Chem Mater. 2003;15(22):4172-80.

28. Bora T, Kyaw HH, Sarkar S, Pal SK, Dutta J. Highly efficient $\mathrm{ZnO} / \mathrm{Au}$ Schottky barrier dye-sensitized solar cells: role of gold nanoparticles on the charge-transfer process. Beilstein J Nanotechnol. 2011;2:681-90.

29. Wei YS, Jin QQ, Ren TZ. Expanded graphite/pencil-lead as counter electrode for dye-sensitized solar cells. Solid-State Electron. 2011;63(1):76-82.

30. Link S, El-Sayed MA. Size and temperature dependence of the plasmon absorption of colloidal gold nanoparticles. J Phys Chem B. 1999;103(21):4212-7.

31. Gong J, Liang J, Sumathy K. Review on dye-sensitized solar cells (DSSCs): fundamental concepts and novel materials. Renew Sustain Energy Rev. 2012;16(8):5848-60.

32. Liu Y, Hagfeldt A, Xiao XR, Lindquist SE. Investigation of influence of redox species on the interfacial energetics of a dye-sensitized nanoporous $\mathrm{TiO}_{2}$ solar cell. Sol Energy Mater Sol Cells. 1998;55(3):267-81. 


\section{Supplementary material}

The following online material is available for this article:

Figure S1 - XRD patterns of TiO2/AuNPs submitted (below) or not to heating at $800 \mathrm{oC}$. Arrows indicate second phase formation.

Figure S2 - XRD pattern of TiO2/AuNPs sample heated at $800 \mathrm{oC}$ (black line) and XRD patterns for anatase (red) and rutile (blue) standards. 